\title{
IMPLEMENTASI TEKNOLOGI KINETIK TURBIN SEBAGAI PENUNJANG KEBUTUHAN ENERGI DI DESA TIRTASARI
}

\author{
Jojo Sumarjo1), Sulistyo Sidik Purnomo2), Insani Abdi Bangsa ${ }^{3)}$, Dian Budhi Santoso3)
}

\begin{abstract}
1)Prodi S-1Teknik Mesin, Fakultas Teknik, Universitas Singaperbangsa Karawang, Karawang, Jawa Barat, Indonesia 2)Prodi S-1 Agroteknologi, Fakultas Teknik, Universitas Singaperbangsa Karawang, Karawang, Jawa Barat, Indonesia 3)Prodi S-1 Teknik Elektro, Fakultas Teknik, Universitas Singaperbangsa Karawang, Karawang, Jawa Barat, Indonesia

Corresponding author : Jojo Sumarjo

E-mail : jojo-sumarjo@staff.unsika.ac.id
\end{abstract}

Diterima 06 April 2021, Direvisi 16 April 2021, Disetujui 17 April 2021

\begin{abstract}
ABSTRAK
Terbatasnya akses dan kebutuhan masyarakat dari penggunaan energi listrik sebagai penerangan jalan pada Desa Tirtasari, Karawang. Maka dirasa perlu ikut berkontribusi dalam pengabdian bidang ilmu dan teknologi. Hal ini untuk memanfaatkan energi baru terbarukan yang ekonomis dengan potensi energi alam sekitar. Oleh karena itu, tujuan dari kegiatan ini merancang alat teknologi berbasis energi turbin kinetik dan energi surya untuk menyelesaikan program ini. Pemanfaatan potensi energi yang dihasilkan dari aliran sungai dapat menghasilkan energi kinetik dari putaran turbin kinetik. Putaran yang dihasilkan dari turbin kinetik menghasilkan energi mekanik ke generator. Sehingga mampu membangkitkan energi listrik, sedangkan arus yang dihasilkan dari solar panel sebagai penggantinya. Maka metode pelaksanaan yang digunakan dalam kegiatan ini berupa pelatihan dan pendampingan pembuatan turbin. Hasil akhir dari kegiatan ini masyarakat dapat mengimplementasikannya secara langsung. Jika sewaktu-waktu aliran sungai mengecil, sehingga tidak mampu memutar turbin kinetik dan generator. Energi yang dihasilkan dari keduanya akan disimpan pada accu. Arus DC (direct current) yang disimpan pada accu akan di konverter menjadi arus AC (alternating current). Maka untuk mendapatkan listrik dengan kapasitas daya maksimum 150 Watt 220V. Adapun luaran dari pengabdian ini adalah terciptanya kemandirian energi dan pengabdian kepada masyarakat.
\end{abstract}

Kata kunci: energi listrik; turbin kinetik; direct current; alternating current.

\begin{abstract}
The limited access and needs of the community from the use of electrical energy as a road lighting in Tirtasari Village, Karawang. So it is considered to have contributed to the dedication of science and technology. This is to utilize the renewable new energy that is economical with the potential of natural energy around. Therefore, the purpose of this activity designed energy-based technology tools kinetic turbine and solar energy to complete this program. The use of energy potential generated from the river flow can produce kinetic energy from the round of kinetic turbines. Rounds produced from kinetic turbines produce mechanical energy to generators. So that it can generate electrical energy, while the current generated from solar panel as a replacement. Then the method of implementation used in this activity is in the form of training and assistance for making turbines. The final result of this activity community can implement it directly. If at any time the river flow is reduced, so it is unable to play kinetic turbines and generators. The energy produced from both will be stored in Accu. The DC (Direct Current) stored on the batteries will be converter into AC (Alternating Current). So to get electricity with a maximum power capacity of 150 watts $220 \mathrm{~V}$. The output of this service is the creation of energy independence and community service.
\end{abstract}

Keywords: electrical energy; kinetic turbine; direct current; alternating current.

\section{PENDAHULUAN}

Pembangkit listrik tenaga air telah banyak dilakukan dalam pengembangan, khususnya berbagai wilayah di Indonesia. Terutama turbin air tipe aliran silang (crossflow) yang penerapannya dapat mencakup semua lokasi dengan debit aliran air dan tinggi jatuh (head) air yang rendah dan menengah (Haimerl, 1960). Di dalam turbin energi kinetik air diganti menjadi energi mekanik. Sehingga air dapat memutar roda turbin (Arismunandar, 2004). Energi puntir yang dihasilkan selanjutnya diganti menjadi energi listrik melalui generator (Luknanto, 2008). Namun demikian selama ini energi air digunakan adalah air dengan tinggi jatuh (head) dan debit besar. Selain itu energi air dengan tinggi jatuh (head) dan debit kecil belum banyak dimanfaatkan. 
Berdasarkan hasil penelitian, bahwa di beberapa wilayah Indonesia memiliki potensi yang cukup besar untuk dikembangkan pembangkit listrik tenaga air dengan tinggi jatuh (head) dan debit kecil (microhydro) (Triono, 2012). Salah satunya di Desa Tirtasari yang berada di Kabupaten Karawang. Terlihat dari kondisi desa yang memiliki sumber daya (berupa air sungai yang deras). Tidak dimanfaatkan dengan baik oleh masyarakat sekitar. Mengingat kebutuhan energi listrik di desa masih belum optimal. Seperti beberapa jalan yang minim akan cahaya penerangan jika di malam hari. Maka Desa Tirtasari dijadikan mitra dalam merealisasikan program pengabdian ini. Dengan tujuan masyarakat dapat memanfaatkan sumber daya energi sekitar lingkungannya. Sehingga dari kegiatan ini masyarakat akan mengetahui pengoptimalan dalam energi listrik.

Turbin ini sangat tepat untuk dipakai pada daerah yang datar yang memiliki aliran sungai, terutama daerah pedesaan. Sampai saat ini dikenal dua jenis turbin kinetik, yaitu turbin kinetik dengan poros horizontal dan turbin kinetik berporos vertikal. Menurut Soenoko (2012), banyak keuntungan yang diperoleh apabila turbin kinetik ini dipakai sebagai pembangkit listrik. Keuntungan pemanfaatan turbin kinetik:

a. Pemilihan lokasi tidak terlalu banyak syarat,

b. Tanpa bendungan,

c. Instalasi yang murah

d. Waktu pemasangan yang cepat,

e. Keluaran energi yang mudah di skala (easily scalable energi output),

f. Kapasitas yang steady, produksi energi yang steady,

g. Bentuknya sederhana dan mudah dibuat,

h. Potensi air yang dibutuhkan tidak membutuhkan tinggi jatuh, yang dibutuhkan hanya adanya aliran air (energi kinetik),

i. Tegangan listrik yang dibangkitkan adalah DC,

j. Pemeliharaan mudah, dan

k. Untuk setiap aliran sungai dapat dipasang beberapa instalasi turbin kinetik.

\section{Pengertian Turbin Kinetik}

Turbin air terdapat pada pembangkit listrik, yang berfungsi untuk mengganti energi potensial menjadi energi kinetik. Maka energi kinetik ini akan menjadi energi elektrik melalui generator sebagai perantaranya (Fox \& Donald, 2011). Turbin air merupakan salah satu mesin penggerak, yang dibantu fluida kerjanya adalah air. Berdasarkan pergantian energi turbin air dibedakan menjadi dua kelompok, yaitu turbin impuls dan reaksi (Badan Pengkajian dan Penerapan Teknologi (BPPT), 2015). Turbin kinetik hanya mengandalkan kecepatan air. Sehingga turbin ini tidak memerlukan tinggi jatuh (head) dari air. Turbin ini dirasa cocok jika dipakai di daerah yang dikelilingi sungai, misalnya pedesaan. Turbin yang dilakukan dalam program pengabdian ini adalah turbin kinetik yang porosnya diletakkan secara vertikal.

\section{Prinsip Kerja Turbin Kinetik}

Prinsip kerja dari turbin kinetik dari arus aliran air yang langsung menumbuk sudu turbin tanpa melalui nozel. Energi yang diberikan kepada sudu berupa energi kinetik/kecepatan (Wiranto \& Kuwahara, 1991). Maka pada turbin kinetik vertikal (tegak) air langsung menumbuk sudu pada setengah bagian yang lain. Selain itu juga mendapatkan tumbukkan, tapi tidak sebesar setengah bagian pertama (Irawan, et al., 2012). Sehingga hal ini turbin masih dapat berputar dengan baik.

\section{Kinerja Turbin Kinetik}

Kinerja dari turbin kinetik berupa air yang masuk ke dalam dan keluar turbin tidak memiliki tekanan lebih (over pressure) (Ohoirenan, et al., 2012). Turbin kinetik yang diamati adalah peralatan mekanis berbentuk roda pada poros vertikal (Sularso \& Tahara, 1983). Dalam pengujian turbin kinetik hasil yang diharapkan akan mendapatkan daya dan efisiensi (Rusman, et al., 2012; Yani, et al., 2012). Beberapa penjelasan pada turbin kinetik sebagai berikut:

a. Daya turbin, ditentukan oleh besarnya debit air dan tinggi jatuh air (head). Selain itu dengan efisiensi dari turbin air tersebut.

b. Debit air, hal yang menjadi penentu dalam perencanaan turbin. Hal ini karena daya yang dihasilkan oleh turbin sangat bergantung pada debit air yang tersedia.

c. Dimensi utama turbin kinetik, standarisasi untuk penentuan turbin kinetik telah ditetapkan. Maka untuk perancangan turbin kinetik ini, cukup mengetahui dimensi dari diameter nozel (d) dan diameter lingkaran tusuk (Dlt).

d. Inverter, bagian dari rangkaian elektronika daya yang digunakan untuk mengonversikan tegangan yang searah (DC), ke tegangan yang bolak-balik (AC). Fungsi dari alat ini dapat mengganti putaran dari motor listrik. 


\section{Penelitian/Pengabdian Terdahulu}

Pengabdian kali ini menerapkan hasil penelitian dalam perancangan turbin kinetik yang telah dilakukan. Sehingga masalah yang terdapat oleh mitra dapat teratasi. Di bawah ini hasil referensi atau rujukan ilmiah dari penelitian/pengabdian terdahulu. Sehingga mendukung dalam terealisasinya program pengabdian ini di Desa Tirtasari. Dengan harapan dari hasil penerapan di masyarakat. Maka menciptakan pembangkit listrik yang bersifat renewable energy, memberdayakan sumber daya alam dan memberikan edukasi kepada masyarakat. Dalam hal memanfaatkan sumberdaya alam yang dijadikan energi listrik alternatif. Hasil dari pengabdian ini sejalan dengan beberapa penelitian yang telah dilakukan sebelumnya. Tentunya mengenai turbin kinetik yang dilakukan pengujian terlebih dahulu (Anam, et al., 2013; Irawan, et al., 2018; Muliawan \& Yani, 2016; Ujiburrahman, et al., 2019; Yani, et al., 2016). Selain itu terdapat beberapa referensi alternatif sebagai bentuk parameter dalam proses pengabdian yang dilakukan (Burhannuddin, et al., 2020; Derwantoro, et al., 2018; Khomsah \& Zuliara, 2015; Oktavianto, et al., 2017; Wiyono, et al., 2018). Adapun tujuan dari pengabdian ini adalah terciptanya kemandirian energi dan pengabdian kepada masyarakat. Dalam hal mengenai pemanfaatan teknologi pembangkit listrik. ekonomis dengan potensi energi alam sekitar.

\section{METODE}

Program pengabdian ini telah dilaksanakan dalam jangka wantu 1 (satu) tahun. Berlokasi di Laboratorium Rekayasa Terpadu, Fakultas Teknik, Universitas Singaperbangsa Karawang dan diterapkan di Desa Tirtasari Karawang. Tahapan awal yang dilakukan adalah studi literatur. Studi literatur ini berisi mengenai kajian penulis dari berbagai macam acuan yang diperoleh. Berupa karya ilmiah, jurnal, buku atau bersumber dari internet. Hal tersebut ada kaitannya dengan topik pengabdian yang berfungsi sebagai penunjang untuk mempermudah dalam proses pengabdian ini. Mitra dalam program pengabdian ini adalah Desa Tirtasari yang terletak di Kabupaten Karawang. Peserta yang terlibat dalam program pengabdian ini adalah masyarakat dari desa tersebut. Mengenai jumlah peserta saat secara langsung dilapangan dibatasi. Hal ini dikarenakan Kabupaten Karawang masih memberlakukan Pembatasan Sosial Berskala Besar (PSBB). Sehingga dalam pelaksanaannya diwakilkan oleh perwakilan desa yang dipilih oleh Kepala Desa Tirtasari.
Metode pelaksanaan kegiatan pengabdian ini berupa pelatihan dan pendampingan pembuatan turbin. Hasil akhir dari kegiatan masyarakat dapat mengimplementasikannya secara langsung disertai dengan bimbingan secara berkala. Dalam melaksanakan kegiatan ini membutuhkan waktu beberapa bulan yang setiap minggunya diadakan beberapa kali pertemuan. Maka untuk memudahkan masyarakat dalam memahami/mengingat materi yang diberikan. Tim membuat bahan ajar berupa poster/modul/diktat sederhana dalam pembuatan turbin untuk pembangkit listrik. Dengan tujuan agar memudahkan masyarakat dalam memahami konsep yang telah ditentukan. Langkah-langkah pelaksanaan dalam kegiatan ini sebagai berikut:

a. Pra Kegiatan/Tahap Persiapan tim melakukan survei lokasi terhadap mitra yang telah ditentukan. Sesuai dengan permasalahan dalam kurangnya mengoptimalkan sumber daya energi listrik. Maka ditentukan mitra dalam program pengabdian ini adalah Desa Tirtasari. Setelah tim melakukan perizinan administrasi dengan Kepala Desa. Selanjutnya tim menyiapkan beberapa alat dan bahan disertai pembekalan materi yang akan disampaikan ke masyarakat. Maka tahap ini dikatakan sebagai studi pendahuluan dan lapangan.

b. Tahap Kegiatan pada tahap ini tim memulai dengan menyampaikan materi yang akan dilaksanakan. Berupa dalam pemanfaatan potensi energi listrik dari sumber daya lingkungan sekitar. Tim membuat forum diskusi kecil yang dihadiri oleh perwakilan desa. Tentunya dalam jumlah peserta yang dibatasi, karena masih diberlakukannya PSBB. Selain itu dengan tetap menerapkan protokol kesehatan sesuai anjuran pemerintah. Dalam pelaksanaannya membutuhkan beberapa kali pertemuan. Tentunya masyarakat masih beradaptasi mengenai materi yang akan langsung diimplementasikan sebagai tahap akhirnya nanti. Setelah cukup dengan materi yang disampaikan dan didapatkan oleh masyarakat. Maka selanjutnya mengimplementasikan dalam pembuatan turbin kinetik yang dapat menghasilkan energi listrik.

c. Tahap Evaluasi dan Monitoring sebagai tahap akhir, tim melakukan pemantauan secara berkala. Hal ini dilakukan agar hasil kegiatan berjalan 
optimal sebagaimana mestinya. Seperti memeriksa kembali alat, bahan, dan pendukung lainnya. Dengan tujuan turbin kinetik dapat digunakan dalam jangka waktu panjang.

Selanjutnya perancangan alat ini menjadi langkah awal untuk menentukan perancangan. Maka perancangan pembangkit

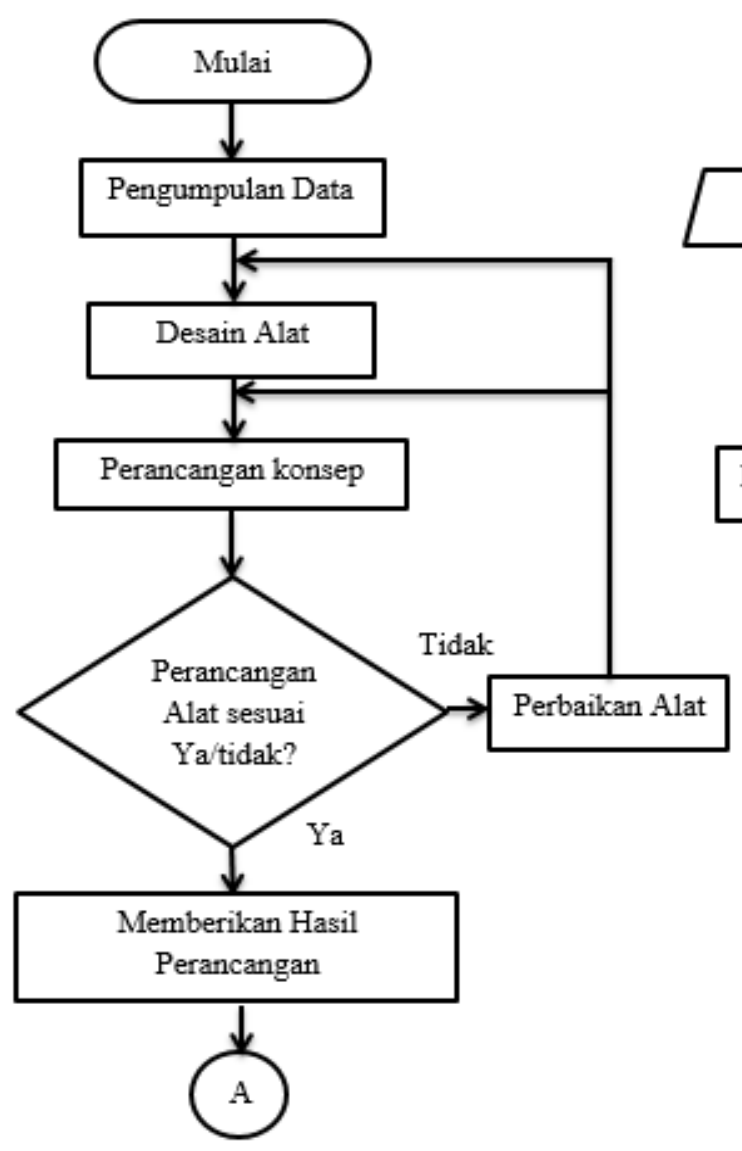

Gambar 1. Diagram Alur Pengabdian

(Sumber : Hasil Pengolahan Penulis) listrik teknologi ini berbasis energi turbin kinetik. Selain itu energi surya sebagai penerangan jalan yang dibuat untuk pembangkit energi terbarukan. Dalam langkah ini penulis harus mempertimbangkan beberapa rancangan. Dengan estimasi dapat beroperasi maksimal jika pembangkit ini telah diterapkan. Berikut diagram alur pengabdian pada Gambar 1. di bawah ini.

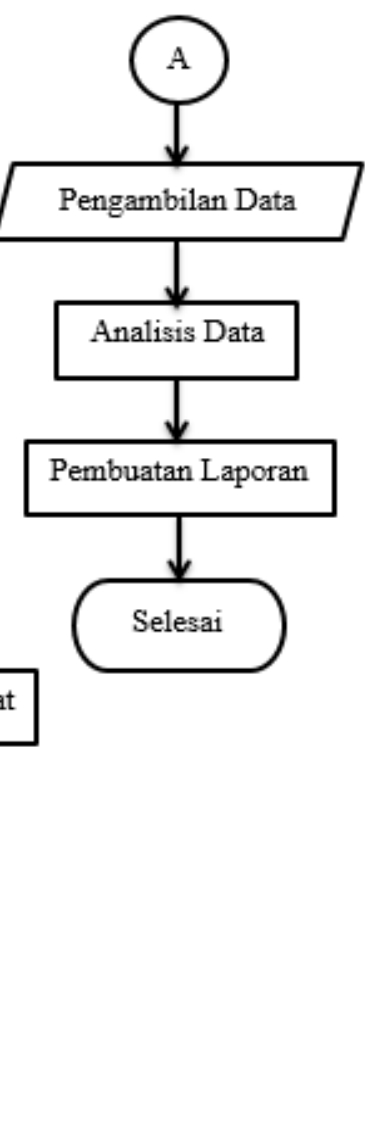

Indikator capaian yang menjadi sasaran adalah menciptakan kemandirian energi di satu daerah. Daerah yang belum mendapatkan akses listrik namun memiliki potensi tenaga listrik yang cukup memadai. Adapun luaran dari pengabdian ini adalah terciptanya kemandirian energi dan pengabdian kepada masyarakat. Dalam hal mengenai pemanfaatan teknologi pembangkit listrik. Kendala yang dihadapi dalam pengabdian ini adalah kondisi pandemi yang saat ini terjadi. Selain itu kondisi iklim yang tidak menentu. Sehingga dalam pengambilan data menunggu kondisi air pasang. Dengan tujuan agar dapat dilakukan pengujian secara maksimal.

\section{HASIL DAN PEMBAHASAN}

Adapun hasil akhir dari program pengabdian yang dilakukan di Desa Tirtasari, Karawang adalah memberikan pendampingan remaja setempat dalam instalasi pembangkit listrik. Pendampingan masyarakat untuk gotong royong dalam instalasi pembangkit. Penerangan jalan umum yang sering dilalui masyarakat. Hal ini untuk memanfaatkan energi baru terbarukan yang ekonomis dengan potensi energi alam sekitar. Oleh karena itu, penulis merancang alat teknologi berbasis energi turbin kinetik dan energi surya untuk menyelesaikan program ini. Pemanfaatan potensi energi yang dihasilkan dari aliran sungai dapat menghasilkan energi kinetik dari putaran turbin kinetik. Berikut hasil perancangan yang telah dilakukan pada Gambar 2. di bawah ini: 


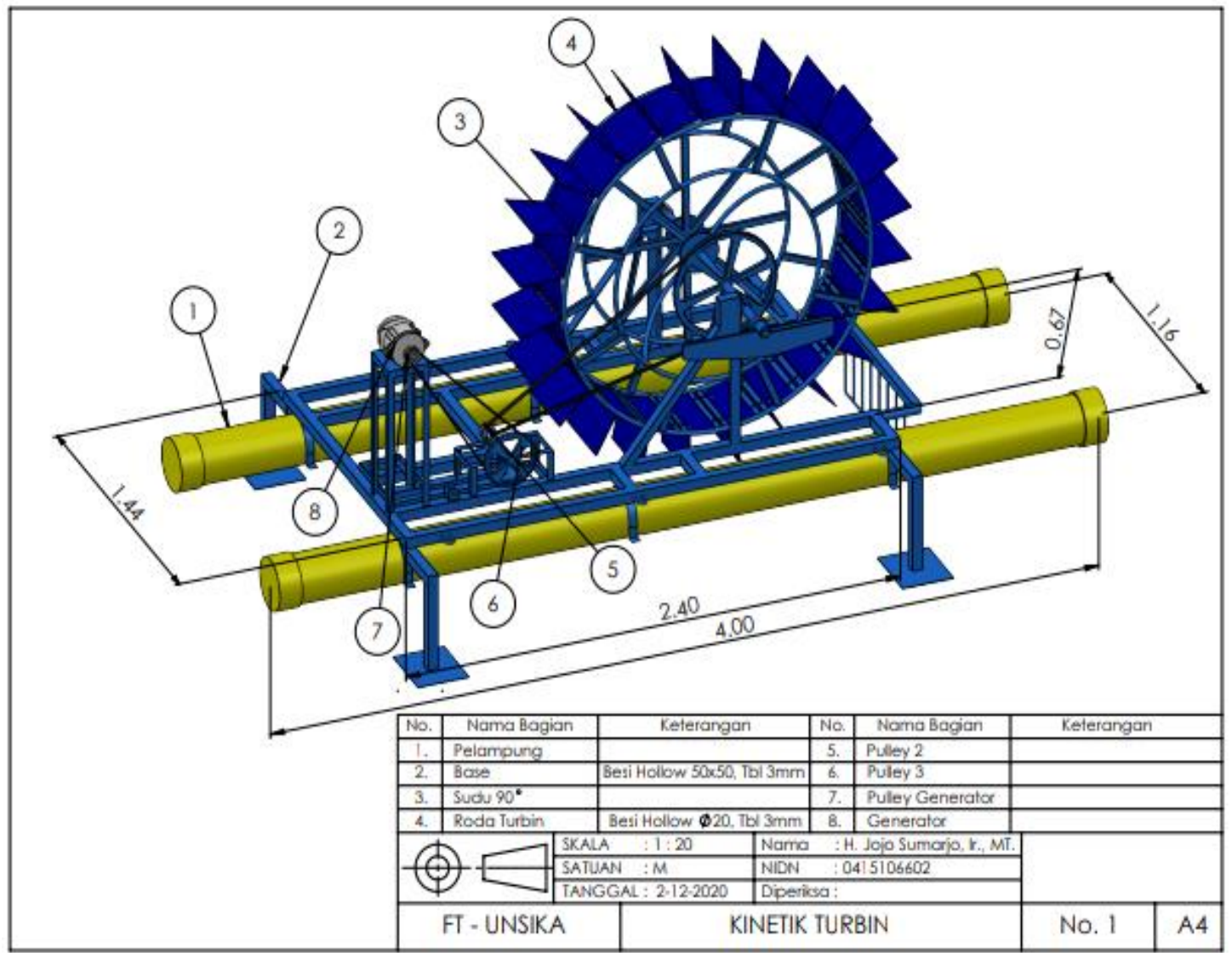

Gambar 2. Bentuk 3D (3-Dimensi) Perancangan Alat Turbin Kinetik (Sumber : Hasil Perancangan Penulis, 2021)

Pada Gambar 2. disebutkan namanama bagian dalam perancagan alat turbin kinetik. Berupa (1) Pelampung, (2) Base, (3) Sudu $90^{\circ}$, (4) Roda Turbin, (5) Pulley 2, (6) Pulley 3, (7) Pulley Generator dan (8) Generator. Hasil perancangan dalam bentuk gambar dengan mempertimbangkan prinsip menggambar teknik. Dengan skala 1:20, satuan $\mathrm{m}$ dan lain-lain. Selanjutnya pada Gambar 3. di bawah ini merupakan dokumentasi kegiatan program pengabdian yang telah dilakukan ;
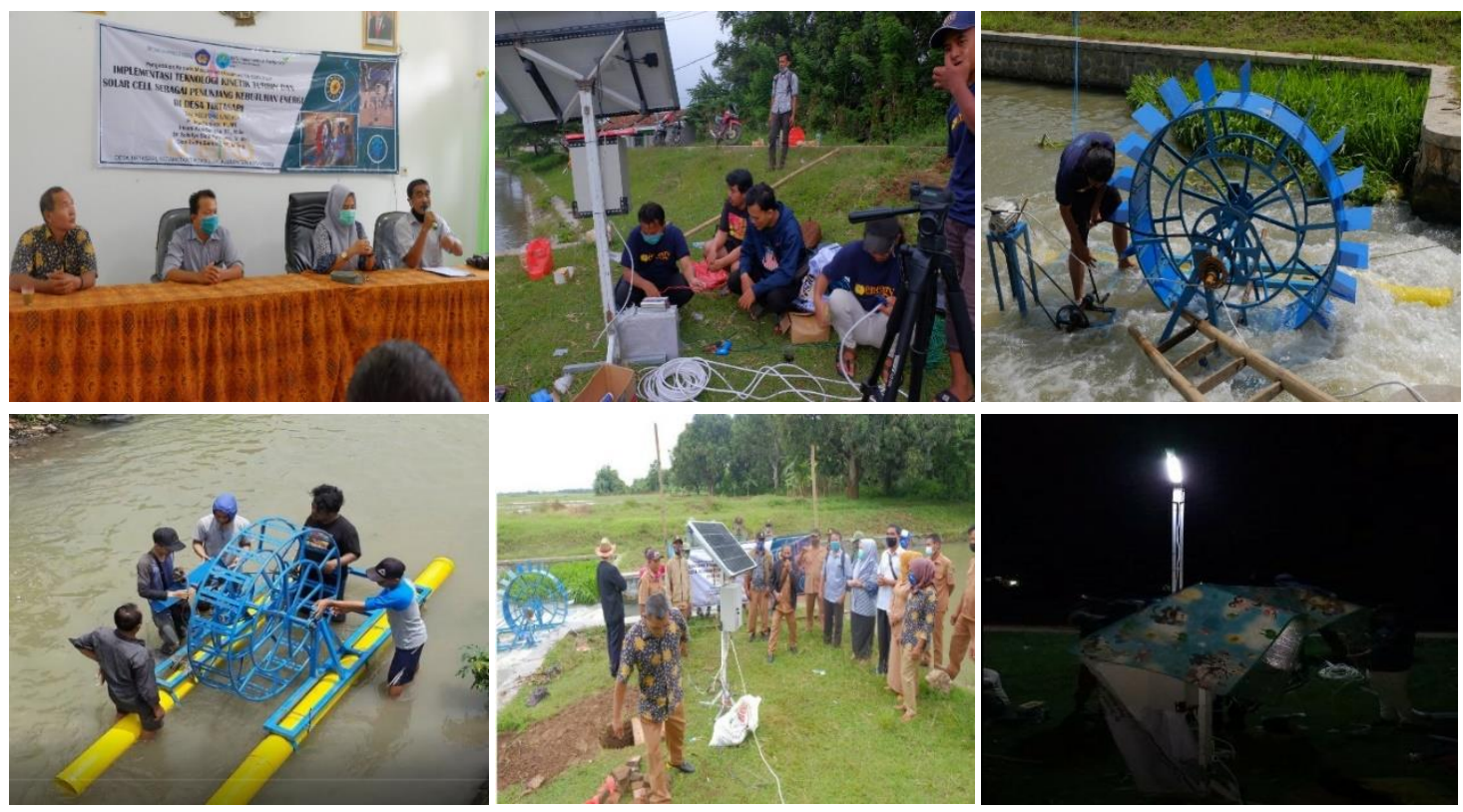

Gambar 3. Dokumentasi Kegiatan Program Pengabdian

(Sumber : Hasil Dokumentasi Penulis, 2021) 
Maka sebagai tahap evaluasi dan monitoring sebagai tahap akhir, tim melakukan pemantauan secara berkala. Hal ini dilakukan agar hasil kegiatan berjalan optimal sebagaimana mestinya. Seperti memeriksa kembali alat, bahan, dan pendukung lainnya. Dengan tujuan turbin kinetik dapat digunakan dalam jangka waktu panjang.

\section{SIMPULAN DAN SARAN}

Dengan adanya kegiatan pengabdian ini, masyarakat mendapatkan beberapa manfaat. Berupa pendampingan remaja setempat dalam instalasi pembangkit listrik. Sehingga menambah akan wawasan terhadap perkembangan teknologi pembangkit energi baru terbarukan. Pendampingan masyarakat untuk gotong royong dalam instalasi pembangkit. Sehingga semakin erat rasa gotong royong antar masyarakat setempat. Penerangan jalan umum yang sering dilalui masyarakat. Dikarenakan selama ini jalan tersebut gelap tanpa adanya penerangan dan rawan tindak kriminalitas. Sehingga dengan adanya program pengabdian ini, masyarakat dapat menikmati penerangan jalan yang disediakan tanpa memikirkan biaya listrik bulanan. Selanjutnya terjalinnya kerjasama mitra antara tenaga pendidik universitas dengan masyarakat setempat. Sehingga terbentuk relasi yang semakin erat antara dunia akademisi dengan masyarakat. Saran ke depannya dengan menambah program sosialisasi dan edukasi dalam perawatan untuk turbin kinetik secara berkala.

\section{UCAPAN TERIMAKASIH}

Ucapan terima kasih tersampaikan kepada Rektor Universitas Singaperbangsa Karawang, Dekan Fakultas Teknik. Selain itu Masyarakat Desa Tirtasari, Kabupaten Karawang. Ucapan terima kasih atas pendanaan dan bantuan pelaksanaan pengabdian kepada masyarakat serta telah mendukung dan mempermudah jalannya program pengabdian yang telah dilakukan.

\section{DAFTAR RUJUKAN}

Anam, A., Soenoko, R. \& Widhiyanuriyawan, D., (2013). Pangruh Variasi Sudut Input Sudu Mangkok terhadap Kinerja Turbin Kinetik. Jurnal Rekayasa Mesin, IV(3), pp. 199-203.

Arismunandar, W., (2004). Penggerak Mula Turbin. 3nd ed. Bandung: Institut Teknologi Bandung (ITB).

Badan Pengkajian dan Penerapan Teknologi (BPPT), (2015). Pusat Teknologi Pengembangan Sumberdaya Energi,
Jakarta: Badan Pengkajian dan Penerapan Teknologi (BPPT).

Burhannuddin, M., Abdulkadir, M. \& Yawara, E., (2020). Merancang, Membuat, dan Meneliti Turbin Gorlov Sumbu Vertikal dengan Profil Naca 0012 dengan Sudut Puntir 45 Derajat. Jurnal Cendekia Mekanika, I(1), pp. 39-45.

Derwantoro, Y., Surendra, D. \& M., Y., (2018). Pembuatan Turbin Double Spherical sebagai Upaya Memperbaiki Kinerja Turbin Spherical. EKSERGI: Jurnal Teknik Energi, XIV(3), pp. 59-65.

Fox \& Donald, M., (2011). Introduction to Fuild Mechanic. 8nd ed. Singapura: John Wiley \& Sons Inc..

Haimerl, L. A., (1960). The Crossflow Turbine. 1st ed. West Germany: Germany.

Irawan, D., Soenoko, R. \& Sutikno, D., (2012). Pengaruh Sudut Sudu terhadap Kinerja Turbin Kinetik. Malang, Prosiding Seminar Nasional Science, Engineering and Technology Universitas Brawijaya.

Irawan, H., Syamsuri \& Q., R., (2018). Analisis Performansi Sistem Pembangkit Listrik Tenaga Air Jenis Turbin Pelton dengan Variasi Bukaan Katup dan Beban Lampu Menggunakan Inverter. Jurnal Hasil Penelitian LPPM Untag Surabaya, III(1), pp. 27-31.

Khomsah, A. \& Zuliara, E. A., (2015). Analisa Teori : Performa Turbin Cross Flow Sudu Bambu 5" sebagai Penggerak Mula Generator Induksi 3 Fasa. Surabaya, Seminar Nasional Sains dan Teknologi Terapan III 2015 - Institut Teknologi Adhi Tama Surabaya.

Luknanto, (2008). Diktat Kuliah Bangunan Tenaga Air, Surabaya: Institut Teknologi Sepuluh November.

Muliawan, A. \& Yani, A., (2016). Analisis Daya dan Efisiensi Turbin Air Kinetis akibat Perubahan Putara Runner. Journal of Sainstek, VIII(1), pp. 1-9.

Ohoirenan, W., Wahyudi, S. \& Sutikno, D., (2012). Pengaruh Variasi Jumlah Sudu terhadap Kinerja Turbin Kinetik Roda Tunggal. Malang, Prosiding Seminar Nasional Science, Engineering and Technology - Universitas Brawijaya.

Oktavianto, D., Budiarto, U. \& Kiryanto, (2017). Analisa Pengaruh Variasi Bentuk Sudu, Sudut Serang dan Kecepatan Arus pada Turbin Arus Tipe Sumbu Vertikal terhadap Daya yang Dihasilkan oleh Turbin. Jurnal Teknik Perkapalan, V(2), pp. 421-430.

Rusman, Soenoko, R. \& Wahyudi, S., (2012). Pengaruh Sudut Aliran terhadap 
Kinerja Turbin Kinetik Bersudu Mangkok. Malang, Prosiding Seminar Nasional Science, Engineering and Technology - Universitas Brawijaya.

Soenoko, R., (2012). Dual Kinetic Turbine Optimization as a Rural Electricity Power Generation. Malang, Prosiding Seminar Nasional Science, Engineering and Technology Universitas Brawijaya.

Sularso \& Tahara, H., (1983 ). Pompa \& Kompresor. 7nd ed. Jakarta: PT. Paradya Paramita.

Triono, M., (2012). Pemodelan Turbin CrossFlow untuk Diaplikasikan pada Sumber Air dengan Tinggi Jatuh dan Debit Kecil. Jurnal Nutrino, IV(2), pp. 1-8.

Ujiburrahman, Soenoko, R. \& Choiron, M. A., (2019). Pengaruh Lebar Sudut Mangkok terhadap Unjuk Kerja Turbin Kinetik. Jurnal Politeknologi, XVIII(3), pp. 315-322.

Wiranto, A. \& Kuwahara, (1991). Pembangkit dengan Tenaga Air. 1st ed. Jakarta: PT. Pradja Paramita.

Wiyono, A. et al., (2018). Karakterisasi Performansi Modifikasi Sudu dan Variasi Head Total Turbin Pelton 9 Sudu. Flywheel: Jurnal Teknik Mesin Untirta, IV(2), pp. 87-90.

Yani, A., Mihdar \& Erianto, R., (2016). Pengaruh Variasi Bentuk Sudu terhadap Kinerja Turbin Air Kinetik (Sebagai Alternatif Pembangkit Listrik Daerah Pedesaan). TURBO: Jurnal Teknik Mesin Universitas Muhammadiyah Metro, V(1), pp. 8-13.

Yani, A., Wahyudi, S. \& Denny, W., (2012). Pengaruh Variasi Panjang Sudu Mangkok terhadap Kinerja Trubin Kinetik. Malang, Prosiding Seminar Nasional Science, Engineering and Technology - Universitas Brawijaya. 